de Boor/Erkel

Zwangsvollstreckung,

Konkurs und Vergleich 


\section{Lieferung}

Reihe C (Rechtswissenschaft)/ Beitrag Nr. 13 


\title{
Zwangsvollstreckung Konkurs und Vergleich
}

\author{
Von \\ DR. HANS OTTO DEBOOR T \\ ehem. o. Professor an der Universität Göttingen \\ Neu bearbeitet von \\ DR. GÜNTHER ERKEL \\ Oberregierungsrat im Hessischen Justizministerium
}

2. Auflage

离

Springer Fachmedien Wiesbaden $\mathrm{GmbH}$ 
ISBN 978-3-663-18757-8

ISBN 978-3-663-19004-2 (eBook)

DOI 10.1007/978-3-663-19004-2

Verlags-Nr. 733

C) Springer Fachmedien Wiesbaden 1962

Ursprünglich erschienen bei Betriebswirtschaftlicher Verlag Dr. Th. Gabler GmbH, Wiesbaden 1962

Softcover reprint of the hardcover 2nd edition 1962 


\title{
Inhaltsverzeichnis
}

\author{
Erster Teil
}

\section{Zwangsvollstreckung}

\author{
Erstes Kapitel \\ Grundlagen
}

$\S 1$ Begriff und Arten der Zwangsvollstreckung . . . . . . . . . . . 13

$\S 2$ Die Vollstreckungsorgane . . . . . . . . . . . . . . . 18

$\S 3$ Voraussetzungen der Zwangsvollstreckung . . . . . . . . . . 23

$\S 4$ Gegenstand der Zwangsvollstreckung . . . . . . . . . . . . 33

$\S 5$ Das Verfahren im allgemeinen . . . . . . . . . . . . . . . 43

\section{Zweites Kapitel}

Die Vollstreckung wegen Geldforderungen

\section{Abschnitt}

Die Vollstreckung in bewegliches Vermögen

§ 6 Grundlagen . . . . . . . . . . . . . . . . . . . . 51

$\S 7$ Die Vollstreckung in körperliche Sachen . . . . . . . . . . 59

$\S 8$ Die Vollstreckung in Forderungen und andere Vermögensrechte . $\quad 65$

§ 9 Mehrfache Pfändung; Verteilungsverfahren . . . . . . . . 73

\section{Abschnitt}

Die Vollstreckung in unbewegliches Vermögen

$\S 10$ Grundlagen . . . . . . . . . . . . . . . . . . . . . . . 75

§ 11 Das Zwangsversteigerungsverfahren $\quad . \quad$. . . . . . . . . . . . . $\quad$. 79 
Seite

§ 12 Versteigerung und Zuschlag . . . . . . . . . . . . . 85

$\S 13$ Die Verteilung des Erlöses . . . . . . . . . . . . . . 91

§ 14 Die Zwangsverwaltung . . . . . . . . . . . . . . . 95

\section{Drittes Kapitel}

Die Vollstreckung wegen anderer Ansprüche

$\S 15$ Die Vollstreckungsmaßnahmen . . . . . . . . . . . . . . . . . 99

\section{Viertes Kapitel}

Arrestund einstweilige Verfügung

$\S 16$ Der Arrest . . . . . . . . . . . . . . . . . . . . 108

$\S 17$ Die einstweilige Verfügung . . . . . . . . . . . . . . . 112

Zweiter Teil

Konkurs und Vergleich

$\S 18$ Einführung . . . . . . . . . . . . . . . . . . . . 117

Erstes Kapitel

Gericht und Beteiligte

$\S 19$ Das Konkursgericht . . . . . . . . . . . . . . . . . . . . . 123

$\S 20$ Der Gemeinschuldner . . . . . . . . . . . . . . . . . 127

$\S 21$ Die Konkursgläubiger . . . . . . . . . . . . . . . . . 133

$\S 22$ Die Organe der Gläubigerschaft . . . . . . . . . . . . 142

$\S 23$ Der Konkursverwalter . . . . . . . . . . . . . . . . 145 
Zweites Kapitel

Seite

Die Konkursmasse

1. Abschnitt

Bestand und Rechtslage

$\S 24$ Der Bestand der Konkursmasse . . . . . . . . . . . . . 153

$\S 25$ Der Konkursbeschlag . . . . . . . . . . . . . . . . 160

$\S 26$ Schwebende Verträge und Prozesse . . . . . . . . . . . 167

2. Abschnitt

Minderung der Masse

$\S 27$ Die Aussonderung . . . . . . . . . . . . . . . . . 174

$\S 28$ Abgesonderte Befriedigung . . . . . . . . . . . . . . 180

$\S 29$ Die Aufrechnung . . . . . . . . . . . . . . . . . . 184

$\S 30$ Die Masseverbindlichkeiten . . . . . . . . . . . . . . 186

\section{Abschnitt}

Vermehrung der Masse durch Anfechtung

§ 31 Die Anfechtungstatbestände . . . . . . . . . . . . . . 190

§ 32 Die Durchführung der Anfechtung . . . . . . . . . . . 197

§33 Die Gläubigeranfechtung außerhalb des Konkurses . . . . . 200

\section{Drittes Kapitel}

Das Konkursverfahren

§ 34 Die Konkurseröffnung . . . . . . . . . . . . . . . . 205

$\S 35$ Verwaltung und Verwertung der Konkursmasse . . . . . . 208

$\S 36$ Die Feststellung der Konkursforderungen . . . . . . . . . 210

$\S 37$ Die Konkursverteilungen . . . . . . . . . . . . . . . 215

§ 38 Die Beendigung des Konkurses . . . . . . . . . . . . . 219

$\S 39$ Der Zwangsvergleich . . . . . . . . . . . . . . . . 222 
Viertes Kapitel

Seite

Besondere Fälle des Konkurses

$\S 40$ Der Konkurs der juristischen Personen . . . . . . . . . . 231

§ 41 Der Konkurs der offenen Handelsgesellschaft . . . . . . . 233

$\S 42$ Der Nachlaßkonkurs . . . . . . . . . . . . . . . . . 236

$\S 43$ Inlands- und Auslandskonkurs . . . . . . . . . . . . . 240

Fünftes Kapitel

Das Vergleichsverfahren zur Abwendung des Konkurses

$\S 44$ Grundlagen . . . . . . . . . . . . . . . . . . . . 243

$\S 45$ Das Verfahren . . . . . . . . . . . . . . . . . . . 248

Sachregister . . . . . . . . . . . . . . . . . . 259 


\section{Abkürzungsverzeichnis}

\begin{tabular}{ll} 
AktG & Aktiengesetz \\
AnfG & Anfechtungsgesetz \\
AO & Abgabenordnung \\
ArbGG & Arbeitsgerichtsgesetz \\
BGB & Bürgerliches Gesetzbuch \\
BGBl. & Bundesgesetzblatt \\
BGH LM & Lindenmaier-Möhring, Nachschlagewerk des Bundes- \\
& gerichtshofs \\
BGHZ & Entscheidungen des Bundesgerichtshofs in Zivilsachen \\
EGZPO & Einführungsgesetz zur Zivilprozeßordnung \\
EheG & Ehegesetz \\
GenG & Genossenschaftsgesetz \\
GG & Grundgesetz \\
GmbHG & Gesetz, betreffend die Gesellschaften mit beschränkter \\
& Haftung \\
GVG & Gerichtsverfassungsgesetz \\
GVGA & Gerichtsvollzieher-Geschäftsanweisung \\
HGB & Handelsgesetzbuch \\
JW & Juristische Wochenschrift \\
KO & Konkursordnung \\
KUG & Kunsturhebergesetz \\
LUG & Literatururhebergesetz \\
MSchG & Mieterschutzgesetz \\
NJW & Neue Juristische Wochenschrift \\
RGBl. & Reichsgesetzblatt \\
RGSt & Entscheidungen des Reichsgerichts in Strafsachen \\
RGZ & Entscheidungen des Reichsgerichts in Zivilsachen \\
RpflG & Rechtspflegergesetz \\
SGG & Sozialgerichtsgesetz \\
StGB & Strafgesetzbuch \\
UWG & Gesetz gegen den unlauteren Wettbewerb \\
VAG & Versicherungsaufsichtsgesetz \\
VglO & Vergleichsordnung \\
VwGO & Verwaltungsgerichtsordnung \\
WG & Wechselgesetz \\
WZG & Warenzeichengesetz \\
ZPO & Zivilprozeßordnung \\
ZVG & Zwangsversteigerungsgesetz \\
& \\
\hline
\end{tabular}

Paragraphen ohne Zusatz sind im ersten Teil solche der Zivilprozeßordnung, im zweiten Teil solche der Konkursordnung. 